\title{
UNA PROBABLE INSCRIPCIÓN LATINA EN UN CASCO DE POZO MORO
}

\author{
POR
}

JAVIER DE HOZ

Universidad Complutense. Madrid

Recientemente se ha publicado, dentro de un estudio de los cascos de tipo Montefortino hallados en la península ibérica, el aparecido en las excavaciones de 1974 en la incineración 2 de la cuadrícula 4F de Pozo Moro, un enterramiento rico, con armas abundantes y fechado por la cerámica griega que contenia entre 375 y 350 a.C. '. El casco de bronce, que se conserva en el Museo Arqueológico Nacional $^{2}$, está fragmentado en varios trozos, los dos mayores formaban la parte superior del capacete, hundida como por un golpe, y la mitad inferior del mismo con el borde bajo bien conservado, en cuya parte interior, en la zona derecha del guardanuca y terminando a poca distancia de las anillas de éste ${ }^{3}$, se encuentra la inscripción a la que están dedicadas estas líneas (fig. 1) ${ }^{4}$.

La existencia de la inscripción y su aspecto general nos eran conocidos hace tiempo gracias a la generosidad de Martin Almagro-Gorbea, su descubridor, que no había dudado en proporcionarnos los datos a los interesados. Yo mismo me había referido a ella en ocasiones, en relación con la escasez de armas con inscripción ibérica y como un argumento más sobre el valor en la escritura meridional del signo

\footnotetext{
'Garcia-Mauriño, J., 1993: "Los caṣcos", págs. 115-116, 124125. $129,134-136,137-138$ y 139.

2 Aún sin número de registro. Pude estudiarlo directamente el 14 de julio de 1994. Agradezco a las conservadoras Alicia Rodero y Magdalena Barril su ayuda y las facilidades de que disfruté. Igualmente agradezco las observaciones de los informantes de $E A E$.

'El borde interior del guardanuca es la zona habitual como soporte de inscripción en este tipo de cascos.

4 No insisto en más detalles arqueológicos, que pueden ser consultados en el articulo cit. de Garcia-Mauriño.
}

que en la levantina se transcribe por be s. Efectivamente con los datos entonces disponibles se imponia la hipótesis obvia de que una inscripción procedente de Pozo Moro debia ser paleohispánica, tal como la interpreta el editor del casco ${ }^{\circ}$. Pero a la vista del excelente dibujo que acompaña la publicación ${ }^{7}$ se plantean serias dudas sobre su caracter ibérico, que la autopsia no hace sino confirmar *

El problema es que se trata de una inscripción (fig. 2) de sólo cinco signos, uno de ellos repetido, poco característicos como tendremos ocasión de ver, y cuya posición en el borde inferior del casco no permite decidir de antemano cuál es la linea de base de la inscripción, que sólo se define por la forma de los signos. Si leemos la inscripción invertida (fig. 3) obtenemos una inscripción paleohispánica admitiendo serias irregularidades en el primero y último signo; si la leemos de acuerdo con la figura 2 las irregularidades desaparecen pero la lectura paleohispánica es imposible y tenemos que aceptar que se trata de una escritura dependiente en último extremo de un alfabeto griego de tipo euboico, como demuestra el tercer signo que, como veremos, resulta esencial para la identificación de la escritura.

La inscripción está cuidadosamente grabada por medio de puntos incisos en el bronce por percusión

\footnotetext{
'P.ej. en la versión original de la $\mathrm{Hoz}$. J., en prensa: «Fl signarion.

" (iarcia-Mauriño, J., 1993: "Los cascos», pág. 115.

' García-Mauriño, J., 1993: «Los cascos", pág. 116.

* En respuesta a mi comunicación Jürgen Untermann me manifiesta carta del 4-7-1994 que considera la inscripción con seguridad itálica, aunque en su opinión, que en este aspecto no comparto, seria o etrusca o eprotosamnita».
} 


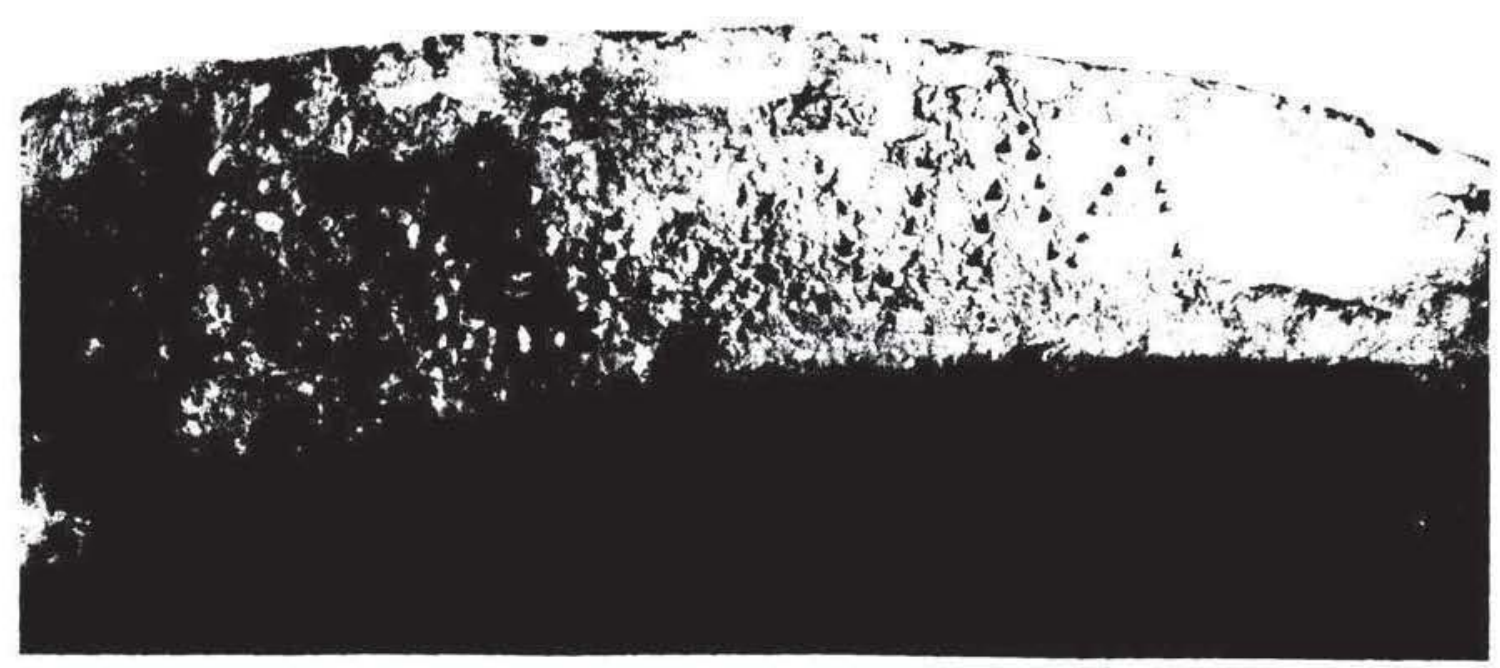

Figura 1.-Guardanuca del casco de Pozo Moro. Foto MAN.

sobre un instrumento profesional ${ }^{9}$, de sección triangular, que ha dejado claramente definida su huella en pequeñas hendiduras muy nitidas cuya superficie corresponde a triángulos isósceles de escasamente $1 \mathrm{~mm}$. de lado. Consta de cinco signos cuya lectura, según la figura 2, es decir de derecha a izquierda, adelanto que debe ser MVLVS.

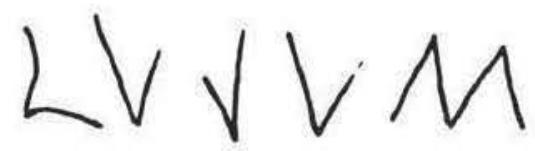

Figura 2. La inscripcion en su posicion de lectura (calco del original).

El primer signo es claramente una $\mathrm{M}$ de cuatro trazos que podria corresponder a las más diversas variantes de alfabetos griegos o derivados del griego. En Italia sin embargo, en el alfabeto etrusco y sus derivados, domina la versión de cinco trazos con la excepción del alfabeto "sudpicénico» y del latino. Veremos más adelante que hay motivos para excluir el sudpicénico, como también un alfabeto griego. En cuanto al latino, la M con cinco trazos no

\footnotetext{
' Los ejemplos de inscripciones sobre armas itálicas o griegas son de sobra conocidos para que merezca la pena insistir en ellos, ef. por ej. CIL = CIL I: 1255, CIL 3609a, y para la época imperial los muchos ejemplos recogidos por McMullen, R., 1960: "Inscripcions». Muchas de estas inscripciones sin embargo son grafitos realizados con un instrumento cortante cualquiera, con trazos más o menos largos y de forma relativamente descuidada, por ej. las dos "sudpicénicas": Mainetti, A., 1985: Le iscrizioni, págs. $252-255$.
}

está atestiguada en las inscripciones del siglo $v$ que emplean ya la de cuatro, y un supuesto ejemplo del siglo Iv (CIL 454) es más probable que sea falisco "1".

Si adoptásemos la lectura de la figura 3 , de izquierda a derecha, podriamos suponer que se trata del signo ibérico meridional cuya versión levantina y celtibérica se lee be, pero los trazos laterales arrancarian demasiado bajo (cf. MLH III 1, tab. 3 sub ŕ en pág. 248) y el único paralelo plausible sería el de algunas inscripciones celtibéricas, demasiado alejadas cronológica, geográfica y culturalmente.

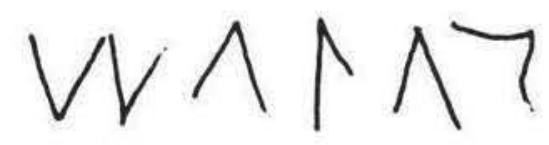

Figurat 3. La inscripcion insertida.

La $\mathrm{V}$ sin tallo y con ángulo agudo es normal en los alfabetos de Italia, mientras que son pocos los griegos que han desarrollado ese tipo y ninguno que pueda justificarse en Hispania en el siglo Iv. En todo caso hay que excluir de los italianos el «sudpicénicon, que ha invertido la posición del signo apuntando el ángulo hacia arriba.

La simplicidad geométrica del signo explica que su forma invertida coincida con otros de valor muy diferente, como la lambda griega clásica o alguna de las variantes de la ka paleohispánica, por lo que su lectura depende enteramente del contexto, lo que a su vez nos lleva a la opción itálica.

${ }^{10}$ Wachter, R., 1987: Altlateinische, pág. 368. 
La $L$ con ángulo inferior es normal en algunos alfabetos griegos arcaicos, entre ellos el euboico del que depende el etrusco y sus transformaciones italianas; de ella, al convertirse el ángulo agudo en recto, nacerá la forma latina clásica que todavía utilizamos. Se trata de un signo por lo tanto esencial para la opción itálica, ya que los alfabetos griegos posibles se excluyen por otros motivos, pero de poco valor clasificatorio dentro de aquélla. Al existir también una forma idéntica invertida, normal en alfabetos griegos y en variantes de la escritura paleohispánica, seguiria teniendo el mismo valor si aceptásemos la lectura de la figura 3 .

El último signo es una $\mathrm{S}$ angular de tres trazos, cuyo trazo inferior es mucho más largo que el superior, apenas apuntado. El tipo es conocido en los alfabetos italianos conviviendo con el redondeado $\mathrm{y}$, como en Grecia, con el de cuatro trazos, mientras que los tipos angulares griegos tienden a utilizar trazos de longitud más homogénea. En Hispania no existe en la escritura meridional pero sí en la ibérica levantina, donde alternan el tipo de cuatro trazos y el de tres en variantes que van de la normal en Grecia a la forma próxima a una $\mathrm{N}$ arcaica levógira (MLH III 1, tab. 2, p. 247). Pero si invertimos la inscripción, de acuerdo con la fig. 3, no sólo tendríamos que admitir un signo claramente levantino, en contradicción con el primero, que de ser hispánico debería ser meridional, sino particularmente mal trazado y además girado sobre su eje vertical.

En conjunto las formas de los signos, a pesar de no estar éstos entre los más explícitos, apuntan a un alfabeto lacial o en todo caso directamente dependiente del latino. Es significativo que todos ellos estén representados precisamente en el único alfabetario latino del siglo iv y a la vez más antiguo conservado, el de Monteroni di Palo ", en las proximidades de Cerveteri, en el que es sensible la diferencia de longitud entre los trazos inferior y superior de la S. La confirmación del abecedario es particularmente bienvenida ya que es dificil hallar paralelos adecuados para nuestra inscripción, porque el número de inscripciones latinas del siglo iv es muy escaso ${ }^{12}$. Incluso en el siglo y medio siguiente, en el que la documentación aumenta considerablemente, el panorama que ofrecen los datos paleográficos es bastante caótico y no permite en absoluto una datación razonablemente segura excepto en los márgenes más amplios ${ }^{13}$. En todo caso con los datos dis-

\footnotetext{
"Ver en el último lugar, con la bibliografia anterior, Lejeune, M., 1988: «Mézence», pág. 50.

${ }_{12}$ Lista en Wachter, R., 1987: Altlateinische, págs. 367-375.

13 Wachter, R., 1987: Altlanteinische, págs. 350-357.
}

ponibles la única objeción que se podria hacer a la hipótesis latina desde el punto de vista de la historia de la escritura estriba en la dirección sinistroversa del texto, pero en realidad sería una objeción mal fundada. De hecho no está nada claro en qué fecha se generaliza la escritura dextrógira en el Lacio, pero hay indicios de que, al menos en zonas marginales y de montana, durante el siglo iv ha podido sobrevivir la escritura levógira, puesto que como demuestra CIL 5 lo hizo la bustrophedon ${ }^{14}$.

Por su parte la forma lingüistica obtenida confirma plenamente esa impresión de latinidad. La lectura final que obtenemos es Mulus, una palabra del léxico latino - de etimología desconocida, pero cuyo uso como cognomen está bien atestiguado ${ }^{15}$ - en nom. como es normal en las inscripciones latinas de propiedad $^{16}$. El testimonio más antiguo correspondia hasta ahora a $M$. Laterius Mulus, mencionado junto con varios miembros de su familia y otros personajes en una defixio de Caere (CIL 2765=ILLR 1148), fechada por uno de ellos, C. Mamilius Limetanus, que según Heurgon seria el tribuno de $-109^{17}$, mientras que Degrassi considera también posible al triumvir monetal de c. $-83^{1 \mathrm{k}}$. Por otra parte la final en - $u s$, sobre cuyo problema cronológico enseguida volveré, excluye cualquier dialecto itálico no latino o paralatino y en etrusco, si bien mulu y su familia son términos corrientes en la epigrafia, no existiría una explicación para la $-s$ final, y el significado de la raiz, "ofrenda, ofrecer", exige alguna indicación complementaria que en nuestro caso el estado de conservación de la parte baja del casco permite afirmar que no ha podido existir.

Aceptando el término como latino o de su inmediato entorno, debe ser obviamente el NP del propietario del casco, pero en las fechas en que nos movemos la expresión cognomen carece de sentido. Habría que pensar más bien en un NP en sentido pleno por sí mismo y por lo tanto en una situación anterior, en la zona de procedencia del propietario o en su grupo social o en ambos, al desarrollo del sistema del nombre gentilicio. La idea no es particularmente atrevida ya que, incluso en la propia Roma, no sabemos exactamente cómo se desarrolló en el tiempo y en la estructura social esa innovación ${ }^{19} \mathrm{y}$ por otra parte la existencia de Mulus como antiguo

\footnotetext{
14 Wachter, R., 1987: Altlanteinische, págs. 110-111.

is Kajanto, 1., 1965: The Latin, págs. 85 y 328.

it Colonna, G., 1983: «Identità», págs. 55-57.

17 Latomus 19, 1960, págs. 220 y ss.

ix ILLR ad loc.

14 Rix, H., 1972: "Zur Ursprung", págs. 741-748; Colonna, G., 1977: «Nome», págs. 180-184.
} 
NP esta indirectamente atestiguada por el gentilicio Mullius, ya conocido en fecha republicana (CIL 1610), IL. RP 520), cuya geminación es normal en gentilicios ${ }^{21}$

Si la cronologia arqueológica del casco es firme, como parece. la mayor dificultad que plantea la interpretación de la inscripción es la final moderna -41 . en ver de -os dominante hasta comienzos del siglo II. Hay que contar sin embargo con fuertes tendencias conservadoras, en especial en la grafia de los NNP en las inscripciones oficiales o solemnes ${ }^{21}$. a pesar de lo cual la forma moderna puede estar ya representada en la primera mitad del siglo III en el sepulcro de Scipio Barbatus (CIL 7) 2 , y existe una inscripcion fechable en el siglo IV (CIL 5) ${ }^{23}$, del territorio de los marsos, precisamente la que nos ha servido como testimonio de escritura levógira, en la que la desinencia de dat. pl. muestra ya la forma -hus en vez de - hos ${ }^{24}$.

El conjunto de los datos que hemos examinado nos lleva a admitir que en el casco de Pozo Moro se gravó en la primera mitad del siglo Iv una inscripción en alfabeto latino $y$ en una lengua que podemos considerar latín en sentido amplio, es decir no necesariamente la lengua de la ciudad de Roma pero si de su mismo ámbito lingüistico, de la que por lo tanto tuvo que ser autor, cuando era propietario del casco, un individuo del Lacio o de sus inmediatos aledaños. No es probable que ese mismo individuo acabase enterrado en Pozo Moro en una tumba típica ibérica, por lo que debemos suponer que en algún momento el casco cambió de propietario y pasó a manos de un ibero. Obviamente las circunstancias en que esto ocurrió son irrecuperables y es dudoso que merezca la pena especular sobre ellas, pero al menos debemos preguntarnos si hay alguna situación histórica conocida que pudo servirlas de marco, porque en ella se diesen contactos reales entre gentes del área ibérica y de la Italia central.

Garcia-Mauriño ha llamado ya la atención, al comentar las posibles vías de llegada a la península ibérica de los cascos tipo Montefortino, sobre el tema

\footnotetext{
20 Schulze, W., 1904 (1966): Zur Geschichte, págs. 422-423 y mención de Mullius en pág. 424.

2 Primer testimonio oficial de - us en CIL 608/9, del -211; vid. Wachter, R., 1987: Altlateinische, pág. 285.

${ }_{22}$ Bibliografia sobre el problema cronológico en CIL $\mathrm{I}^{2}$ fasc. 4 , ad loc., y añadir Wachter, R., 1987: Alllateinische, págs. 303342 y 357.

${ }^{23} \mathrm{Vid}$. ahora las reproducciones fotográficas en $\mathrm{CIL} \mathrm{I}^{2} 4$, tab. II fig, 1, e Italia, 1989: pág. 322, figs. 230-231.

24 Wachter, R., 1987: Altlateinische, págs. 310,358 y 370 Por el contrario la lectura - us en ILRP 1274a es un error corregido por el propio Degrassi, vid. CIL 4, 2835.
}

de los mercenarios *. Por otra parte algunos estudios recientes insisten en que la adopción de ciertos tipos de armas en la peninsula ibérica durante el siglo i demuestra que la influencia itálica en sentido amplio era intensa ${ }^{2 h}$, aunque por ahora no parece que se hayan detectado cauces y causas precisos de esa influencia. En el caso de los cascos tipo Montefortino la inscripción de Pozo Moro puede representar un indicio significativo a favor de que su introducción en la Peninsula se produjo también desde Italia, y no desde el área céltica, sin que naturalmente pueda extrapolarse esa idea a la cuestión polémica del origen último del tipo. Sin embargo el horizonte cronológico de los cascos es posterior al de otros tipos de armas itálicas adoptadas y adaptadas por los iberos, y no entra en mi competencia el decidir si se trata de fenómenos relacionados o no. Con los datos actualmente existentes creo que la explicación más sencilla de nuestra inscripción supone que el casco en que se encuentra pasó de manos de un propietario italiano a manos de un mercenario ibérico, que regresó con él a su patria para terminar enterrado en Pozo Moro ${ }^{27}$.

Admitiendo la fecha arqueológica del casco, la ocasión de la presencia en Italia de nuestro mercenario debe estar relacionada con las actividades de Dionisio 1 de Siracusa, que como es sabido contó con mercenarios ibéricos citados en las fuentes en numerosas ocasiones ${ }^{2 x}$, y cuyo enfrentamiento con los etruscos dio lugar a acciones militares en la zona central de la propia Península que probablemente no quedaron reducidas a la que de entre ellas adquirió celebridad, el saqueo del santuario y puerto de Caere en Pyrgi en el 384 (Aristot. Oecon. II 1349b; D. S. XV 14, 3-4; Polyaen. V 2, 21; Aelian. Var. hist. 1 20; Str. V 2, 8; Serv. Aen. X 184), sino que darían lugar probablemente a escaramuzas de menor importancia en otros puntos más meridionales, en las que pudo producirse el "traspaso" del casco, ello sin contar con que, dada la permeabilidad de la Italia de la época, no hay que olvidar otras actividades de Dionisio, en concreto en el Adriático, en la 
Italia meridional o en (oreega $2 "$. y que cabe incluso que el propietario latino del casco fuese a su vez un mereenario desplazado de su lugar de origen. ya que aunque normalmente sólo se piensa desde este punto de vista en las gentes samnitas ". nada se opone a que también los habitantes del reborde montañoso del Lacio practicasen ese oficio. Obviamente tampoco podemos excluir un mero fenómeno de comercio ". mientras no tengamos más datos sobre en qué medida jugaban un papel en el mercado antiguo los objetos de segunda mano.

\section{REFERENCIAS BIBLIOGRÄICAS}

Colonna, G., 1977: «Nome gentilizio e società», SE 45, $175-92$

_ : 1983: «Identità come appartenenza nelle iscrizioni di possessso dell Italia preromana», Epigraphica 45, 49-64.

Dr:irAssi, A., 1965², 1963: Inscriptiones Latinae Liberae Rei Publicae. Firenze.

Garcia y BHLlido, A., 1952: "El mundo de las colonizaciones", Historia . .. Menéndez Pidal I 2 , 279-680.

24 (t. las referencias bibliograficas recientes en la pàg. 590 de Musti. D.. 1992: Storia.

tw Por ej. Pallottino, M.. 1984: Storia, pág. 145.

"No hay que olvidar que los cascos de Benicarló proceden de un pecio, aunque de fecha ya romana, y (iarcia-Mauriño ha insistido para el conjunto de los cascos en ambos modos de transmisión, el mercenariado y el comercio, 1993: "Los cascos". pag. 134, y sobre los pecios. págs. 139142. (i RRO II-M RIVO. J. 1993: "Los cascos de tipo Montefortino en la Peninsula lbérica. Aportación al estudio del armamento de la $\mathrm{II}^{+}$Fidad del Hicrrom, complutum 3, 95-146.

Ho\%, J. I) . en prensa: «EI signario hispánico meridionaln, en Homenaje a.J. Maluquer.

ILLRP=DI (iRAssI, A., 1965: 1963: Inscriptiones. Italia omnium terrarum parens, 1989: Milano.

K.AvI(), I., 1965: The Latin (ognomina, Helsinki.

$\mathrm{K} \backslash \mathrm{R} \downarrow /, \mathrm{W} . \mathrm{S}$., «Elementos etrusco-itálicos en el armamento ibéricom, La presencia . 187-95.

Lı $11 \mathrm{NI}$, M., 1988: "Mézence, d’un zêta à l'autre», REL. 66, 50-4.

MAc Mutu.1 N, R., 1960: "Inscripcions on Armor and the Supply of Arms in the Roman Empire», $A J A$ 60, 23-40.

MarinetTI, A., 1985: Le iscrizioni sudpicene, Firenze.

Mustı, D., 1992: Storia greca, Roma-Bari.

Pal.lottino, M., 1984: Storia della Prima Italia. Milano.

La presencia de material etruscos en la Peninsula Iherica, 1991: Coords. J. Remesal \& O. Musso, Barcelona.

QuisaDs, F., 1991: «En torno al origen y procedencia de la falcata ibérican, La presencia , 475541.

- 1992: Arma y simbolo: la Falcata Ihérica, Alicante.

- : en prensa: "Vias de contacto entre la Magna Grecia e Iberia: la cuestión del mercenariado».

Rıx, H., 1972: «Zur Ursprung des römisch-mittelitalischen Gentilnamensystems», ANRW1 2, 700. 58.

Scmul.1., W., 1904 (1966): Zur Geschichte Lateinischer Eigennamen, Berlin/Zürich/Dublin.

WAcItter, R., 1987: Altlateinische Inschrifien, Bern. 